\title{
Decision making under catastrophic risk and learning: the case of the possible collapse of the West Antarctic Ice Sheet
}

\author{
M.-L. Guillerminet • R. S. J. Tol
}

Received: 11 August 2005 / Accepted: 11 June 2008 / Published online: 18 September 2008

(C) The Author(s) 2008. This article is published with open access at Springerlink.com

\begin{abstract}
A collapse of the West-Antarctic Ice Sheet (WAIS) would cause a sea level rise of 5-6 m, perhaps even within 100 years, with catastrophic consequences. The probability of such a collapse is small but increasing with the rise of the atmospheric concentrations of greenhouse gas and the resulting climate change. This paper investigates how the potential collapse of the WAIS affects the optimal rate of greenhouse gas emission control. We design a decision and learning tree in which decision are made about emission reduction at regular intervals: the decision makers (who act as social planners) have to decide whether to implement the environmental or not (keeping then the flexibility to act later). By investing in the environmental policy, they determine optimally the date of the optimal emission reduction. At the same time, they receive new information on the probability of a WAIS collapse and
\end{abstract}

This work was conducted while M.-L. Guillerminet was with the Research unit Sustainability and Global Change, Hamburg University.

The algorithm is available upon request and can be sent by the authors.

M.-L. Guillerminet $(\bowtie) \cdot$ R. S. J. Tol

Research Unit Sustainability and Global Change,

Hamburg University and Centre for Marine and Atmospheric Science,

Hamburg, Germany

e-mail:ml_guillerminet@yahoo.fr

R. S. J. Tol

e-mail: richard.tol@esri.ie

R. S. J. Tol

Economic and Social Research Institute, Dublin, Ireland

R. S. J. Tol

Institute for Environmental Studies, Vrije Universiteit, Amsterdam, The Netherlands

R. S. J. Tol

Engineering and Public Policy, Carnegie Mellon University, Pittsburgh, PA, USA 
the severity of its impacts. The probability of a WAIS collapse is endogenous and contingent on greenhouse gas concentrations. We solve this optimisation problem by backward induction. We find that a potential WAIS collapse substantially bring the date of the optimal emission reduction forward and increases its amount if the probability is high enough (a probability of $1 \%$ per year for the worst case), if the impacts are high enough (a worst case damage of $10 \%$ of GDP for a $3^{\circ} \mathrm{C}$ warming) or if the decision maker is risk averse enough (for example a social damage due to pollution equal to $1 \%$ GDP for an atmospheric temperature of $3^{\circ} \mathrm{C}$ ). We also find that, as soon as a WAIS collapse is a foregone fact, emission reduction falls to free up resource to prepare for adapting to the inevitable. By contrast, adaptation (such as building dikes along the coast) postpones policy intervention because that strategy reduces the risk of catastrophic damages.

\section{Introduction}

The possibility of a catastrophe is one of the main reasons for concern about climate change (Smith et al. 2001; Wright and Erickson 2003). The climate is a non-linear system. It may be that the gradual change in the concentrations of greenhouse gases caused by human activities will bring about abrupt changes in atmosphere, ocean, or biosphere. Examples include the "runaway" greenhouse effect, in which climate change triggers massive releases of greenhouse gases (Harvey and Huang 1995), a shutdown of the thermohaline circulation (Keller et al. 2004; Oppenheimer 1998; Alley et al. 2003), and the disintegration of the West Antarctic Ice Sheet (WAIS), the topic of this paper. Although the process of disintegration is slow at a human time-scale, once it has been set in motion, there is no way of stopping the WAIS from disintegrating entirely. A WAIS collapse would lead to a sea level rise of 5-6 m, but probably not faster than within the course of one century. A 5-m sea level rise would have drastic impacts. This paper analyses how the risk of a WAIS collapse influences the optimal control of carbon dioxide emissions.

Besides the uncertainty about the collapse of the WAIS, we also consider the uncertainty about the damage costs. Uncertainty interacts with irreversibility, another key feature of climate change decision-making. On the one hand, carbon dioxide emission reduction is a sunk cost to society. Sunk costs create an opportunity cost of adopting a policy now rather than waiting for more information about the impacts of warming and their economic consequences. On the other hand, part of the atmospheric stock of carbon dioxide is not degradable. Emissions have irreversible impacts on the atmosphere, and climate change may well have further irreversible impacts. Adopting an abatement policy now rather than later has a sunk benefit, because the society is better protected from irreversible environmental damages. These opportunity costs (benefits) bias traditional cost-benefit analysis against (in favour) of policy adoption. We investigate which bias is stronger.

In this paper, we limit the response options of decision makers to either doing nothing (or rather, waiting for more information about the future) or adopting an environmental policy (i.e. reducing emissions/building dikes such that the probability of having another catastrophe is equal to zero). We do not distinguish between reducing emissions and building dikes. We focus on this second question by taking into account irreversibilities under uncertainties, which modify the traditional cost- 
benefit analysis. We then assume that the reduction quantity is already known, and that there is an international cooperation in order to reduce emissions: the model is global and deals with one decision maker who faces international social costs of warming.

To do so, we use a Real Options model, introduced by Arrow and Fischer (1974) and Henry (1974). They show that there is a premium or option value on policies to maintain flexibility. We follow Pindyck (2000, 2002) and Saphores (2004): irreversibility and environmental uncertainty can strongly influence the timing of environmental policy. This policy aims to minimize social costs in the presence of continuous and catastrophic damages. In the set-up of Pindyck (2000, 2002; see also Dixit and Pindyck 1994, ${ }^{1}$ and Yin and Newman 1996), the probability of a disaster only strengthens the discount rate. They show that, if environmental uncertainty increases, an investment in emission reduction should be delayed because of sunk costs. In contrast, Saphores (2004) shows that acting earlier to reduce GHGs emissions may be optimal in order to avoid long-term damages due to the GHGs accumulation (i.e., sunk benefits).

We choose here to consider this kind of problem by focusing on the report of IPCC (2001), which highlighted that the extreme weather events have increased in severity and frequency during the twentieth century as the atmospheric GHGs concentration has gone up. So our aim is to determine what to decide (i.e. when to adopt an environmental policy as well as how much GHGs emissions reductions should be optimal) according to what has already happened. Baranzini et al. (2003) include the possibility of exogenous climatic shocks into a Real Options model. Keller et al. (2004) consider uncertainty on the globally averaged temperature for a doubling of atmospheric $\mathrm{CO}_{2}$ (as well as on damages after the thermohaline circulation collapse). However, the probability and magnitude of catastrophes are based on agents' behaviour, i.e. catastrophic risk is endogenous in this area. In Tsur and Zemel (1996) and Fisher and Narain (2003), the possibly catastrophic impacts depend on atmospheric gases concentration, which in turn depend on emissions and emission control. They also distinguished two kinds of catastrophes (high damage and low damage). In this paper, we add that the probability of a catastrophe ${ }^{2}$ depends on the occurrence of catastrophes in previous periods. In this manner, we simulate that an extreme climate scenario, in our case the collapse of the West-Antarctic Ice Sheet, would manifest itself through a series of floods that would increase in frequency (and intensity) but still be random.

As in Werey (2000), who studies endogenous probabilities of failures of water hubs, we combine Real Options and Operational Research approaches. We compare over 100 years social costs when a policy is adopted (and then no catastrophe occurs anymore) and when nothing is done (and then the society has to cope with possible disasters that could increase these social costs). We adopt the policy when social costs are minimized.

\footnotetext{
${ }^{1}$ See more precisely Chapters 3 (pp. 85-87), 4 (pp. 112-114) and 6 (pp. 199-204).

${ }^{2}$ We follow Fisher and Narain $(2003$, p. 1) to describe a catastrophe: "The increase in global mean temperature is expected to lead to disruptions in the world's climate. Whether these disruptions will cause economic damages and whether these damages will be catastrophic in nature is as yet uncertain. There are those who believe that global warming will lead to sudden and catastrophic economic damages. Others believe that damages will be modest".
} 
Other papers on catastrophic risks of climate change include Gjerde et al. (1999) and Baranzini et al. (2003). These papers ignore stochasticity. In return, the representation of emission reduction is more sophisticated than what is possible here.

In Section 2 we present the model, hypotheses and data retained. We state results and the sensitivity analysis in Section 3. We conclude in Section 4.

\section{The model and data}

\subsection{The model}

Cost-benefit analysis is a standard framework to evaluate environmental policies, although by no means the only contender. Our cost-benefit model incorporates three essential characteristics of the investment problem:

- Irreversibilities: The benefits of an environmental policy are sunk for the society (due to an immediate adoption), and so are its costs.

- Uncertainties over future outcomes: The evolution of the coupled human-nature system is uncertain; the evolution of GHGs concentration depends on the implementation or not of the environmental policy; frequency and magnitude of disasters are uncertain; social costs of climatic changes are unknown. Finally, two random events are possible: (mild or bad) catastophy or no catastrophy.

- Delay: The adoption on policy can be delayed. At each point in time, two decisions are possible: implementing the environmental policy or waiting.

The model aims to adopt a GHGs abatement policy at the optimal time, i.e. when the social costs are minimized (Pindyck 2000, 2002). This decision is unique and is not compounded as a series of sequential investment decisions. In contrast to Werey (2000), we fix a terminal boundary. The policy has to be adopted no later than year 100 .

The information structure of the problem is as follows. There is uncertainty on social costs and on the probabilities and magnitudes of damages, variables that depend on the temperature and so on the concentration of greenhouse gases.

Let $M(t)$ denote the stock of environmental pollutants. ${ }^{3}$ According to Nordhaus (1994), ${ }^{4}$ the present stock of pollutant $M(t)$ evolves as:

$$
M(t)=M(0)+\beta E(t)+(1-\alpha)[M(t-1)-M(0)],
$$

where $M(0)=596.4$ billions tons of $\mathrm{CO}_{2}$ is the initial stock of $\mathrm{CO}_{2} ; M(t-1)$ is the stock of $\mathrm{CO}_{2}$ in the previous period; $E(t)$ is emissions of $\mathrm{CO}_{2} ; \beta$ is the marginal atmospheric retention ratio; $\alpha$ is the natural rate at which the stock of $\mathrm{CO}_{2}$ dissipates over time.

\footnotetext{
${ }^{3}$ Note that we use "stock" and "concentration" interchangeably; the two are not the same, but there is a one-to-one relationship between them. In the model, we use the stock.

${ }^{4}$ We ignore later, more complicated models of carbon cycle and climate (e.g., Nordhaus and Boyer 2000). We only take carbon dioxide into account.
} 
World GDP grows over time at a rate of $2 \%$ per year. We express social costs, damages and investment costs in percentage of GDP. Emissions $E(t)$ increase over time if no policy is implemented:

$$
E(t)=(1+\delta) E(t-1),
$$

with $\delta=0.5 \%$ or $1 \%$ per year. That is, carbon efficiency improves by $1.0 \%$ or $1.5 \%$ per year.

When the policy is adopted at time $t *$, emissions $E(t)$ are reduced from $0.1 \%$ to $1.1 \%$. Then they begin to grow again but at a lower rate than for the baseline

$$
\begin{gathered}
E\left(t^{*}\right)=(1-\eta) E\left(t^{*}-1\right), \text { with } \eta \in[0.1 \% ; 1.1 \%], \text { and } \\
E(t+1)=(1+\gamma) E(t) \text { for } t>t^{*}, \text { with } \gamma<\delta \text { and } \gamma=0.1 \% .
\end{gathered}
$$

The costs $K$ of a $1 \%$ emission reduction are equal to $0.02 \%$ of GDP (Tol 2008).

The climate system is characterized by a multi-layer system comprising the atmosphere, the mixed layer of oceans and the deep oceans. Nordhaus (1994) models the evolution of the temperature of the atmosphere and the upper ocean layers by the following equation:

$$
T(t)=T(t-1)+\sigma_{1}[f(t)-\lambda T(t-1)]-\sigma_{2}\left[T(t-1)-T_{L O}(t-1)\right],
$$

where $\sigma_{1}=1 / R_{1}$ with $R_{1}$ the thermal capacity of atmosphere and upper oceans; $\sigma_{2}=R_{2} / \tau_{2}$ with $R_{2}$ the thermal capacity of deep oceans and $1 / \tau_{2}$ the transfer rate from the upper layer to the lower layer; $\lambda$ is the climate feedback parameter;

$T_{L O}$ is the temperature of the deep ocean:

$$
T_{L O}(t)=T_{L O}(t-1)+\sigma_{3}\left[T(t-1)-T_{L O}(t-1)\right],
$$

with $\sigma_{3}=1 / \tau_{2}$.

The radiative forcing due to carbon dioxide (relative to 1990) follows

$$
f(t)=\frac{\mu}{\ln 2} \ln \left(\frac{M(t)}{M(0)}\right) \text { with } \mu=0.99 .
$$

The social costs of warming depend on the temperature (cf. Fisher and Narain 2003). Climate change brings damages. There are three potential states of nature in each year: no catastrophe, mild catastrophe and bad catastrophe.

Without a catastrophe, damage costs depend on temperature:

$$
C(t)=c T^{2} \text {. }
$$

The parameter $c$ is set such that a warming of $3^{\circ} \mathrm{C}$ implies damages equal to $1 \%$ of GDP, which roughly corresponds to the values found in the survey by Smith et al. (2001). If a mild (bad) catastrophe occurs, the parameter c is multiplied by 3 (11), for that year. Note that the damage cost convexity can be interpreted as the risk aversion of society against disasters.

The risk of catastrophic damages is endogenous, in the sense that the probability of the damages occurring depends on the stock of GHGs, which is endogenous in our model. Following Fisher and Narain (2003), the probability of the occurrence of a catastrophe is:

$$
p(t)=\left(2 /\left(1+e^{-b(t) M(t)}\right)\right)-1 .
$$


The present probability, i.e. for $M(0)$, of a disaster equals $1 \%$. The probability rises to $5 \%$ for $2 M(0)$. So, $b(t)$ evolves over time as

$$
b(t)=b(t-1)+b(t-1) \frac{M(t)-M(t-1)}{M(t-1)} \frac{\log \frac{0.5}{1.5}-2 \log \frac{0.9}{1.1}}{2 \log \frac{0.9}{1.1}} .
$$

If $p(t)$ is the probability to have a disaster at time t, then $p(t) k(N(t))$ is the probability that this is a bad disaster, where:

$$
k(N(t))=q+0.8 N(t), \text { with } k(N(t)) \in[0 ; 1] .
$$

The probability of a bad catastrophe increases linearly with the number of bad catastrophes in the past $[N(t)$, with $0 \leq N(t) \leq t]$. This is because, once the WAIS starts to collapse, chances are it will continue. However, a really bad flood may also just be a freak event. A WAIS collapse would manifest itself by bad floods becoming ever more common, but the first bad floods are not necessarily a sign that the WAIS is collapsing. ${ }^{5}$ Note that $[1-k(N(\mathrm{t}))]$ is the conditional probability of a mild catastrophe.

Finally, relevant issues on risk-management strategies in the face of uncertain thresholds are here how (1) the temperature trigger the threshold risk and (2) what is the threshold specific damage. We assume that the WAIS may collapse without additional greenhouse gas emissions, but with a very low probability. The threshold risk and the threshold specific damage are endogenous in this study, increasing with temperature. Unlike Keller et al. (2004), we do no explicitly consider the uncertainty about temperatures or $\mathrm{CO}_{2}$ levels. Instead, we include these uncertainties in the probabilities of the WAIS collapse and the damages.

\subsection{Solution}

The decision tree has 100 periods, but we present the two periods case for illustration in Fig. 1. The squares represent decision nodes (adopting a policy $\mathrm{P}$ or not NP), and circles represent stochastic nodes (the occurrence of catastrophes D or not ND).

After adopting a policy, emissions, concentrations and temperatures evolve differently. $C_{P}(t)$ and $C_{P}(t+1)$ denote the social costs involved by a policy adopted at time t. $C_{N P, P}(t+1)$ are social costs when the policy is only adopted at time $(t+1), C_{N P}(t)$ and $C_{N P}(t+1)$ are social costs when the policy is not adopted. Note that investment costs $K$ are made at the beginning of the period, so they have to be discounted by the discount rate $r$.

Social costs of damages depend on the number of disasters that have already occurred and that modify the probability of having high damages (which involve social costs $D_{h}$, whereas $D_{l}$ denotes social costs due to mild damages). So, social damages after the occurrence of one catastrophe at time $t$ equal

$$
D_{D}(t)=k(t, 1) D_{h}(t)+[1-k(t, 1)] D_{l}(t) .
$$

\footnotetext{
${ }^{5}$ The detection of early warning signs for a WAIS collapse is an area of active research. The collapse of ice-shelves (De Angelis and Skarca 2003) or the rapid warming of ocean waters feeding the iceshelf cavity may have a much higher signal to noise ratio then the occurrence of floods (p. 5).
} 


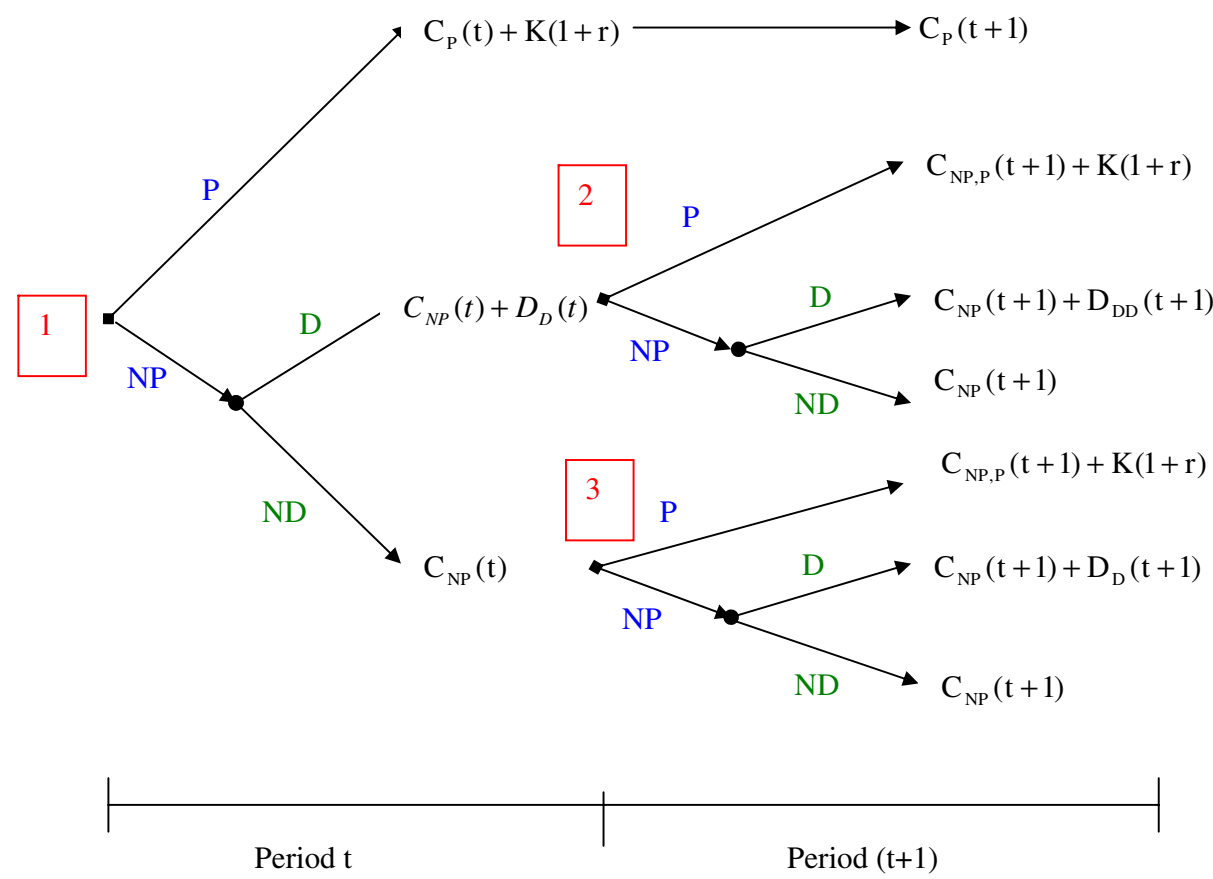

Fig. 1 The sequential decision framework over two periods. We begin by choosing the better solution at nodes 2 and 3 (evaluated at time $t=0$ ), which is the one that minimizes social costs occurred in period $(t+1)$ and after. At node 2 :

$\min$ Node2

$$
=\min \left\{\begin{array}{l}
K\left(\frac{1}{1+r}\right)^{t}+C_{N P, P}(t+1)\left(\frac{1}{1+r}\right)^{t+1}+\ldots ; \\
{\left[p(t+1)\left(C_{N P}(t+1)+D_{D D}(t+1)\right)+(1-p(t+1)) C_{N P}(t+1)\right]\left(\frac{1}{1+r}\right)^{t+1}+\ldots}
\end{array}\right\} .
$$

At node 3:

$\min$ Node 3

$$
=\min \left\{\begin{array}{l}
K\left(\frac{1}{1+r}\right)^{t}+C_{N P, P}(t+1)\left(\frac{1}{1+r}\right)^{t+1}+\ldots ; \\
{\left[p(t+1)\left(C_{N P}(t+1)+D_{D}(t+1)\right)+(1-p(t+1)) C_{N P}(t+1)\right]\left(\frac{1}{1+r}\right)^{t+1}+\ldots}
\end{array}\right\} .
$$

Finally at node 1 (evaluated at time $t=0$ ), decision makers choose between implementing the policy or waiting at time $t$ according to:

$$
\min \text { Node } 1=\min \left\{\begin{array}{c}
K\left(\frac{1}{1+r}\right)^{t-1}+C_{P}(t)\left(\frac{1}{1+r}\right)^{t}+C_{P}(t+1)\left(\frac{1}{1+r}\right)^{t+1}+\ldots ; \\
p(t)\left[\left(C_{N P}(t)+D_{D}(t)\right)\left(\frac{1}{1+r}\right)^{t}+\min N o d e 2\right] \\
+(1-p(t))\left[C_{N P}(t)\left(\frac{1}{1+r}\right)^{t}+\min N o d e 3\right]
\end{array}\right\} .
$$

(This equation is the same at time $t+1$ when nothing happens at the time $t$.) Social damages after the occurrence of a second catastrophe at time $(t+1)$ when a disaster has already arrived at time $t$ equal

$$
D_{D D}(t+1)=k(t+1,2) D_{h}(t+1)+[1-k(t+1,2)] D_{l}(t+1) .
$$


The optimal strategy minimizes expected net present total costs. It is computed using the algorithm of averaging-out-and-folding-back (which is available upon request to the authors).

Finally at time $t$, decision makers choose between implementing the policy or waiting at time $t$ according to optimal social costs $\mathrm{SC}^{*}(t)$ which are the minimum social costs occurred in period $t$ and after:

$$
S C^{*}(t)=\min \left\{\begin{array}{l}
K\left(\frac{1}{1+r}\right)^{t-1}+\sum_{s=t}^{100}\left(C_{P}(s)\left(\frac{1}{1+r}\right)^{s}\right) \\
p(t)\left[\left(C_{N P}(t)+D_{D}(t)\right)\left(\frac{1}{1+r}\right)^{t}+S C_{D}^{*}(t+1)\right] \\
+(1-p(t))\left[C_{N P}(t)\left(\frac{1}{1+r}\right)^{t}+S C^{*}(t+1)\right]
\end{array}\right\} .
$$

Note that $S C_{D}^{*}(t+1)$ are the optimal social costs at $(t+1)$ when a catastrophe occurred during the previous period (involving an increase of the probability of a bad catastrophe, not only due to the increase of atmospheric stock of GHGs).

Depending on the number of catastrophes that have already happened, we can deduce when it is optimal to choose to invest in an environmental policy: When the social costs of implementing a policy are less than the social costs of waiting.

We do not evaluate option values here. Option values represent the difference between results of one shot analysis (i.e. either investing right now or never, result evaluated by the net present value) and a sequential decision framework. The decision for the first period is affected by the prospect of future learning about climatic events. Option values are positive if more development proceeds with more complete information than without it. We know that in case of options to invest, option values are always positive even with risk aversion (cf. Pindyck 2000). It is worth taking into account the arrival of information to the future. See for example Schimmelpfennig (1995) who evaluates option values in a two periods framework of two possible choices.

\subsection{Data and parameters}

We calibrate our model on the basis of hypotheses and results obtained by Nordhaus (1994), Nordhaus and Boyer (2000), Tol (2002a, b) and Fisher and Narain (2003). See Table 1.

\section{Results}

Table 2 shows the optimal time of investment as a function of the number of catastrophes occurring. For comparison, Table 2 also displays the marginal, net present cost of waiting and policy implementation. Decision makers start choosing between implementation and waiting for further information at $t=0$. At the optimal time $t^{*}$, the costs of implementing an environmental policy are always lower than costs of waiting.

Costs fall if the number of catastrophes decreases, which has as a result to postpone the implement of the environmental policy. If no catastrophe occurs, it is 
Table 1 Parameters, values, and sources

\begin{tabular}{|c|c|c|}
\hline Parameters & Initial values & References \\
\hline \multicolumn{3}{|c|}{ Initial atmospheric stock and emissions of GHGs, initial temperatures } \\
\hline $\begin{array}{l}\text { Initial atmospheric stock of greenhouse gases } \\
M(0) \text { (billions tons of } \mathrm{CO}_{2} \text { equivalent) }\end{array}$ & 785.3 & Fisher and Narain (2003) \\
\hline $\begin{array}{l}\text { Initial emissions } \mathrm{E}(0) \text { (billions tons } \\
\text { of } \mathrm{CO}_{2} \text { equivalent) }\end{array}$ & 6.1587 & Nordhaus and Boyer (2000) \\
\hline $\begin{array}{l}\text { Initial atmospheric temperature } \\
T(0) \text { (Celsius degrees) }\end{array}$ & 0.58 & Fisher and Narain (2003) \\
\hline $\begin{array}{l}\text { Initial ocean temperature } T_{L O}(0) \\
\quad \text { (Celsius degrees) }\end{array}$ & 0.07 & Fisher and Narain (2003) \\
\hline \multicolumn{3}{|c|}{ Present atmospheric stock of GHGs $M(t)=M(0)+\beta E(t)+(1-\alpha)[M(t-1)-M(0)]$} \\
\hline $\begin{array}{l}\text { Natural rate } \alpha \text { (between } 0 \text { and } 1) \text { at which the } \\
\text { stock of } \mathrm{CO}_{2} \text { dissipates over time }\end{array}$ & 0.02 & Nordhaus (1994) \\
\hline Marginal atmospheric retention ratio $\beta$ & 0.9 & Nordhaus (1994) \\
\hline \multicolumn{3}{|l|}{ Emissions } \\
\hline Emissions growth rate $\delta, E(t)=(1+\delta) E(t-1)$ & 0.005 & This study \\
\hline If an environmental policy is implemented at $t^{*}:$ & & This study \\
\hline $\begin{array}{l}\text { Rate of emissions reduction } \eta \\
\qquad E\left(t^{*}\right)=(1-\eta) E\left(t^{*}-1\right)\end{array}$ & 0.011 & \\
\hline $\begin{array}{l}\text { Then emissions increase at a lower rate } \\
\qquad \gamma<\delta, E(t+1)=(1+\gamma) E(t) \text { for } t>t^{*}\end{array}$ & 0.001 & \\
\hline \multicolumn{3}{|l|}{ Temperatures } \\
\hline \multicolumn{3}{|l|}{$\begin{array}{l}\text { Temperature parameters of the atmosphere, } \\
\begin{aligned} T(t) & =T(t-1)+\sigma_{1}[f(t)-\lambda T(t-1)] \\
& -\sigma_{2}\left[T(t-1)-T_{L O}(t-1)\right]\end{aligned}\end{array}$} \\
\hline$\sigma_{1}$ & 0.1 & Nordhaus (1994) \\
\hline$\sigma_{2}$ & 0.1 & Nordhaus (1994) \\
\hline \multicolumn{3}{|l|}{$\begin{array}{l}\text { Temperature parameters of the upper ocean layers, } \\
T_{L O}(t)=T_{L O}(t-1)+\sigma_{3}\left[T(t-1)-T_{L O}(t-1)\right] \\
\text { and } f(t)=\frac{\mu}{\ln 2} \ln \left(\frac{M(t)}{M(0)}\right)\end{array}$} \\
\hline$\sigma_{3}$ & 0.1 & Nordhaus (1994) \\
\hline$\lambda$ & 0.1 & Nordhaus (1994) \\
\hline$\mu$ & 0.99 & Nordhaus (1994) \\
\hline \multicolumn{3}{|l|}{ Costs } \\
\hline $\begin{array}{l}\text { Costs of a policy adoption } K(\% \text { GDP }) \\
\text { for } 1 \% \text { emissions reduction }\end{array}$ & 0.02 & Tol (2008) \\
\hline $\begin{array}{l}\text { Parameter } \mathrm{c} \text { of social costs of pollution } \\
C(t)=c T^{2}(1 \% \text { GDP when } T=3)\end{array}$ & 0.001 & Nordhaus (1994) \\
\hline \multicolumn{3}{|l|}{ Damage costs } \\
\hline Parameter $h$ of $C(t)=h T^{2}(10 \%$ GDP when T $=3)$ & 0.01 & This study \\
\hline Parameter $l$ of $C(t)=h T^{2}(2 \%$ GDP when T $=3)$ & 0.002 & This study \\
\hline \multicolumn{3}{|l|}{ Initial parameters of probabilities of catastrophes } \\
\hline $\begin{array}{l}\text { Initial probability of a WAIS collapse }[p(0) \cdot q] \text {, } \\
\text { i.e. for } M(0) \text {, of a disaster equals } 1 \%\end{array}$ & 0.01 & This study \\
\hline Initial probability of a disaster, $p(0)$ & 0.1 & This study \\
\hline $\begin{array}{l}\text { Initial probability q that this disaster provokes } \\
\text { a high-costly damage }\end{array}$ & 0.1 & This study \\
\hline \multicolumn{3}{|l|}{ Others parameters } \\
\hline Discount rate $r(\%)$ & 5 & This study \\
\hline GNP growth rate gnp & 0.02 & This study \\
\hline
\end{tabular}




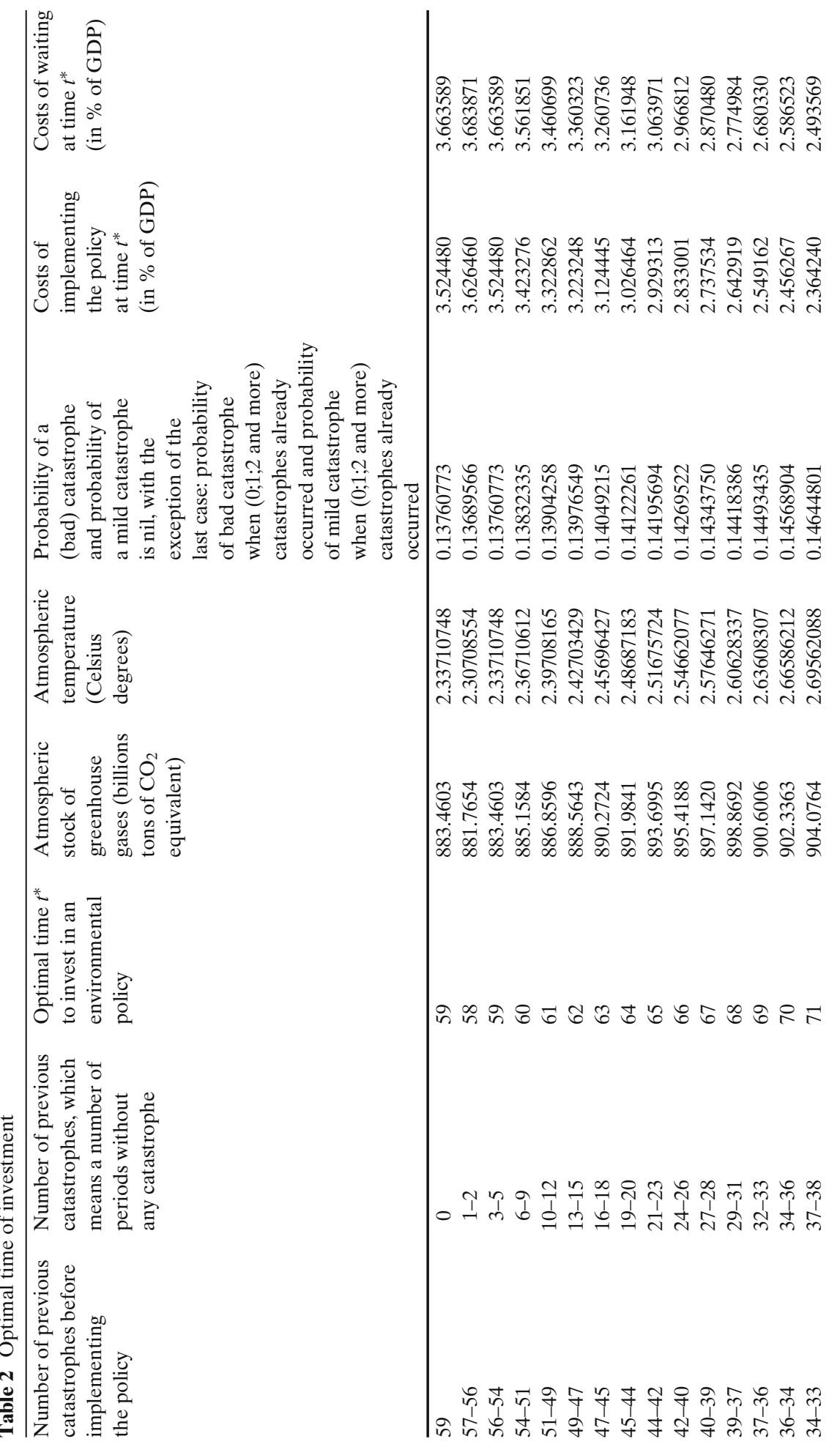




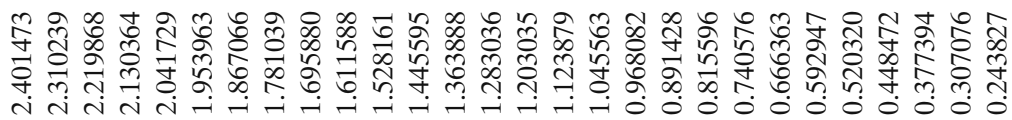

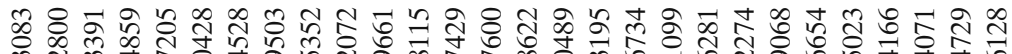

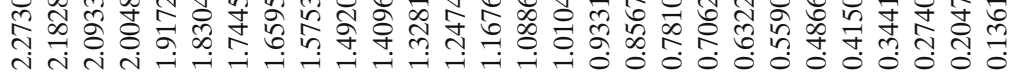

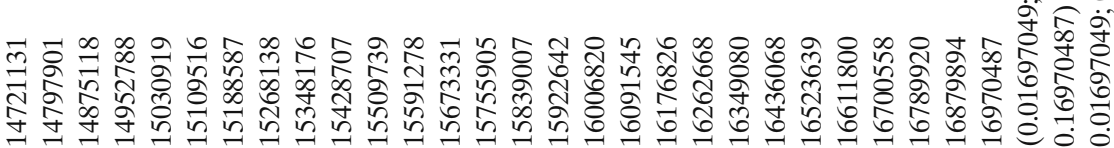

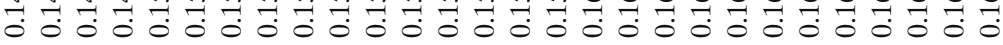

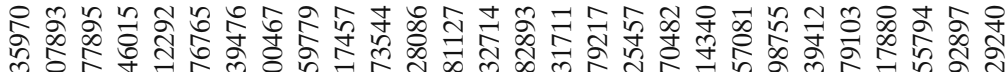

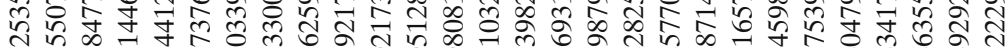

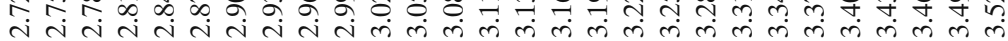

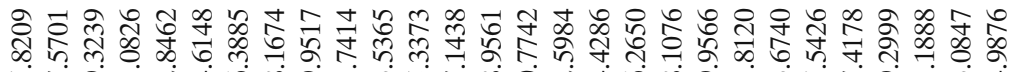

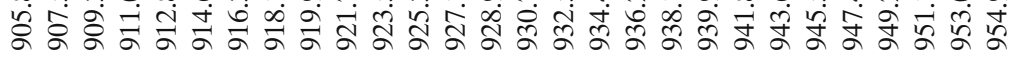

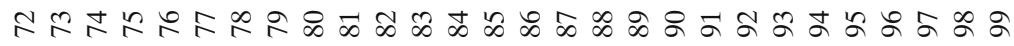

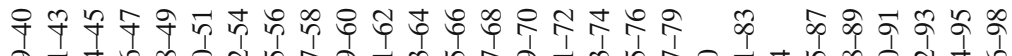

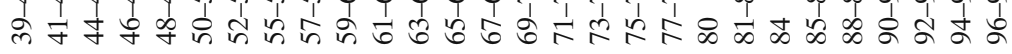

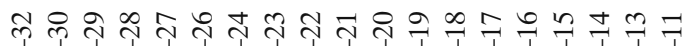

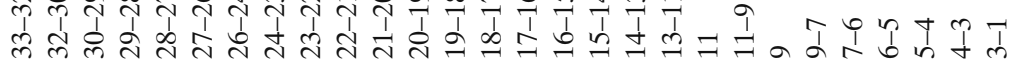


better to wait until time $t=100$. That is, catastrophes are the main reason for reducing greenhouse gas emissions in our model.

The optimal time to implement a policy is equal to the 59th year when 59 catastrophes have already occurred; to the 58th year when 57 or 56 catastrophes have already occurred; and to the 59th year with 56,55 or 54 previous catastrophes. This is due to the probability of having a catastrophe, which is a concave function between 0 and 1 . When catastrophes are very numerous, the probability of having another one is very similar regardless of the exact number of previous catastrophes. Therefore, the costs of waiting can be lower than the costs of implementing a policy (which takes into account the capital costs). Decision makers can invest later (at $t^{*}=59$ instead 58).

However, generally, emission reduction is postponed to later periods if fewer catastrophes occur. The earliest time for abatement is after 58 years, which is relatively late. Therefore, emission reduction is not used to prevent a WAIS collapse, but only to reduce damages. Emission reduction delays WAIS collapse, but does not avoid it. This is similar to the case of low thermohaline circulation collapse damages in Keller et al. (2004). This effect is due to the choice of damage representation. If the unlikely, bad catastrophe is avoided, then the less unlikely mild catastrophe could still occur. And if that one is avoided too, then there are still the impacts of regular climate change. Combined with exogenous probabilities, the expected damage is continuous too.

Table 3 contains the results of a sensitivity analysis. Emission reduction is implemented earlier if (1) the costs of emission abatement are lower and (2) the time horizon is shorter. If emissions grow faster, less catastrophes are needed to induce implementation.

Uncertainty gives rise to two different issues. One issue relates to risk aversion. The fact that one cannot undo past emission reduction or actively completely remove carbon from the atmosphere is irrelevant to the optimal regulatory strategy (Kolstad 1996). The other issue relates to uncertainty where that uncertainty is being resolved over time, i.e. information is being acquired over time. The literature on irreversibilities tells us that with learning, we should avoid decisions that restrict future options.

The results obtained with the assumption of risk aversion show that an environmental policy involves two kinds of irreversibilities that work in opposite directions:

- Sunk costs associated with an environment regulation: policies aimed at reducing ecological damage impose sunk costs on society;

- Sunk benefits of avoided environmental degradation: environmental damage can be partially or totally irreversible. So adopting a policy now rather than waiting has a sunk benefit (a negative opportunity cost).

When there is no GDP growth over time, implementation is earlier. A higher discount rate implies earlier implementation. Note that lower (or no) economic growth and a higher (consumption) discount rate are equivalent. A higher discount rate implies reduced care for the future. The higher preference for the present is equivalent to a lower value for the future, i.e. a lower value of waiting for more information. Finally, the option value decreases and decision makers invest earlier. Emission reductions are implemented earlier. 
Table 3 Sensitivity analysis

\begin{tabular}{|c|c|c|}
\hline $\begin{array}{l}\text { Variations of } \\
\text { parameters }\end{array}$ & $\begin{array}{c}\text { Impact on the optimal time }{ }^{\mathrm{a}} \\
t^{*} \text { of implementing the policy } \\
\text { compared to } t^{*}=59 \text { (with } 0 \text { period } \\
\text { without any catastrophe) }\end{array}$ & $\begin{array}{l}\text { Present value of } \\
\text { implementing the policy } \\
\text { at time } t^{*} \\
\text { (in \% of GDP) }\end{array}$ \\
\hline \multicolumn{3}{|l|}{ Emissions } \\
\hline \multicolumn{3}{|c|}{ Emissions growth rate $\delta=0.005, E(t)=(1+\delta) E(t-1)$} \\
\hline $0.6 \%(>)$ & $\begin{array}{c}< \\
t^{*}=58 \\
58-56 \text { catastrophes, which means } \\
0-2 \text { periods without any catastrophe }\end{array}$ & $>$ \\
\hline $0.8 \%$ & $\begin{array}{c}< \\
t^{*}=58 \\
58-55 \text { catastrophes, which means } \\
0-3 \text { periods without any catastrophe }\end{array}$ & $>$ \\
\hline $1 \%$ & $\begin{array}{c}< \\
t^{*}=58 \\
58-54 \text { catastrophes, which means } \\
0-4 \text { periods without any catastrophe }\end{array}$ & $>$ \\
\hline $1.1 \%$ & $\begin{array}{c}\quad< \\
t^{*}=58 \\
58 \text { catastrophes, which means } 0 \text { period } \\
\text { without any catastrophe }\end{array}$ & $<$ \\
\hline $1.4 \%$ & $\begin{array}{c}< \\
t^{*}=58 \\
58 \text { catastrophes, which means } 0 \text { period } \\
\text { without any catastrophe }\end{array}$ & $<$ \\
\hline \multicolumn{3}{|c|}{ Intensity of emissions reduction: $\eta=0.011, E\left(t^{*}\right)=(1-\eta) E\left(t^{*}-1\right)$} \\
\hline $0.1 \%(<)$ & $=$ & $\begin{array}{c}> \\
3.526846\end{array}$ \\
\hline $0.2 \%$ & $=$ & $\begin{array}{c}> \\
3.526610\end{array}$ \\
\hline $0.3 \%$ & $=$ & $\begin{array}{c}> \\
3.526373\end{array}$ \\
\hline $0.4 \%$ & $=$ & $\begin{array}{c}> \\
3.526137\end{array}$ \\
\hline $0.5 \%$ & $=$ & $\underset{3.525900}{>}$ \\
\hline $0.6 \%$ & $=$ & $\begin{array}{c}> \\
3.525664\end{array}$ \\
\hline $0.7 \%$ & $=$ & $\begin{array}{c}> \\
3.525427\end{array}$ \\
\hline $0.8 \%$ & $=$ & $\underset{3.525190}{>}$ \\
\hline $0.9 \%$ & $=$ & $\begin{array}{c}> \\
3.524954\end{array}$ \\
\hline $1.0 \%$ & $=$ & $\begin{array}{c}> \\
3.524717\end{array}$ \\
\hline $1.2 \%(>)$ & $=$ & $\begin{array}{c}< \\
3.524243\end{array}$ \\
\hline $1.3 \%$ & $=$ & $\begin{array}{c}< \\
3.524006\end{array}$ \\
\hline
\end{tabular}


Table 3 (continued)

\begin{tabular}{lcc}
\hline $\begin{array}{l}\text { Variations of } \\
\text { parameters }\end{array}$ & $\begin{array}{c}\text { Impact on the optimal time } \\
t^{*} \text { of implementing the policy } \\
\text { compared to } t^{*}=59 \text { (with } 0 \text { period } \\
\text { without any catastrophe) }\end{array}$ & $\begin{array}{c}\text { Present value of } \\
\text { implementing the policy } \\
\text { at time } t^{*}\end{array}$ \\
\hline
\end{tabular}

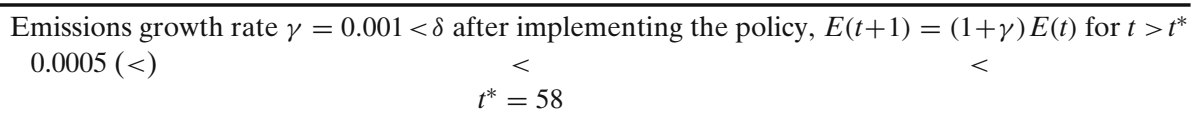

58-56 catastrophes, which means

$0.002(>)$

0-2 periods without any catastrophe

$0.005(>)$

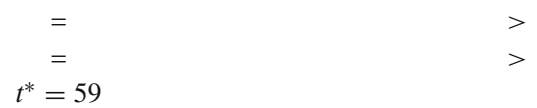

59-55 catastrophes, which means

0-4 periods without any catastrophe

No emissions reduction $\eta=0$ and same emissions growth rate $\gamma=\delta=0.005$

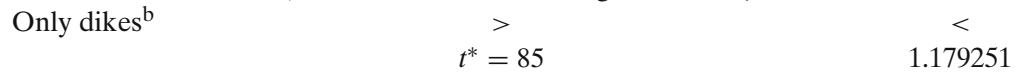

85-84 catastrophes, which means

Costs

0-1 periods without any catastrophe

Costs of a policy adoption $K=0.02$ ( $\%$ GDP) for $1 \%$ emissions reduction

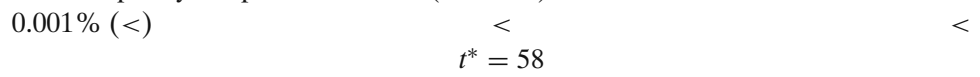

58-56 catastrophes, which means

$0.01 \%(<)$

0-2 periods without any catastrophe

$0.1 \%(>)$

$\begin{array}{ll}= & < \\ = & > \\ > & >\end{array}$

$1 \%(>)$

Risk neutrality: parameter c of social costs of pollution $C(t)=c T(1 \%$ GDP when $T=3)$ 0.003

Catastrophes
No catastrophe
at all, $p(t)=0$$$
\begin{aligned}
> & > \\
t^{*} & =85
\end{aligned}
$$
1.16760

85-83 catastrophes, which means

0-2 periods without any catastrophe

No slide of the

$$
\begin{gathered}
> \\
t^{*}=85
\end{gathered}
$$

$\forall \mathrm{N}(\mathrm{t})$ the number of $\quad 85-83$ catastrophes, which means

previous catastrophes $0-2$ periods without any catastrophe

Probability of a bad catastrophe $q$ [with $k(1)=0.9$ and $k(2)=1$ ]

$$
\begin{aligned}
& 0.05(<) \\
& 0.15(>)
\end{aligned}
$$$$
\begin{aligned}
& = \\
& < \\
t^{*} & =58
\end{aligned}
$$

$<$

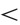

58-56 catastrophes, which means

0-2 periods without any catastrophe

Probability of a bad catastrophe $q$ [and $k(1), k(2)$ are adjusted]

$$
\begin{aligned}
& 0.05[<; k(1)=0.85 \\
& \text { and } k(2)=1] \\
& 0.15[>; k(1)=0.95 \\
& \text { and } k(2)=1]
\end{aligned}
$$

$=$

$>$ 
Table 3 (continued)

\begin{tabular}{|c|c|c|}
\hline $\begin{array}{l}\text { Variations of } \\
\text { parameters }\end{array}$ & $\begin{array}{l}\text { Impact on the optimal time } \\
t^{*} \text { of implementing the policy } \\
\text { compared to } t^{*}=59 \text { (with } 0 \text { period } \\
\text { without any catastrophe) }\end{array}$ & $\begin{array}{l}\text { Present value of } \\
\text { implementing the policy } \\
\text { at time } t^{*} \\
\text { (in } \% \text { of GDP) }\end{array}$ \\
\hline \multicolumn{3}{|c|}{ Evolution of the probability of a bad catastrophe according to previous catastrophes: $k(1)$ and $k(2)$} \\
\hline$k(1)=0.8(<)$ and $k(2)=1$ & $=$ & $=$ \\
\hline$k(1)=1(>)$ and $k(2)=1$ & $=$ & $>$ \\
\hline & $t^{*}=59$ & \\
\hline & 59-58 catastrophes, which means & \\
\hline & $0-1$ periods without any catastrophe & \\
\hline \multicolumn{3}{|l|}{ Others parameters } \\
\hline \multicolumn{3}{|l|}{ Discount rate $r=5 \%$} \\
\hline $4 \%(<)$ & $>$ & $>$ \\
\hline $8 \%(>)$ & $<$ & $<$ \\
\hline \multicolumn{3}{|l|}{ GNP growth rate $g n p=0.02$} \\
\hline 0, no GNP growth, $(<)$ & $\begin{array}{c}< \\
t^{*}=46 \\
46-43 \text { catastrophes, which means } \\
0-3 \text { periods without any catastrophe }\end{array}$ & $\begin{array}{c}< \\
1.286666\end{array}$ \\
\hline $4 \%(>)$ & $\begin{array}{c}> \\
t^{*}=70 \\
70-64 \text { catastrophes, which means } \\
0-6 \text { periods without any catastrophe }\end{array}$ & $\begin{array}{c}> \\
12.519976\end{array}$ \\
\hline \multicolumn{3}{|l|}{ No GNP growth and } \\
\hline $\begin{array}{l}\text { a lower discount } \\
\text { rate }(r=4 \%)\end{array}$ & $\begin{array}{c}< \\
t^{*}=52 \\
52-50 \text { catastrophes, which means } \\
0-2 \text { periods without any catastrophe }\end{array}$ & $\begin{array}{c}< \\
2.051516\end{array}$ \\
\hline $\begin{array}{l}\text { A higher discount } \\
\text { rate }(r=6 \%)\end{array}$ & $\begin{array}{c}< \\
t^{*}=40 \\
40-39 \text { catastrophes, which means } \\
0-1 \text { periods without any catastrophe }\end{array}$ & $\begin{array}{c}< \\
0.883048\end{array}$ \\
\hline \multicolumn{3}{|c|}{ Number of periods, $T=100$, of the decision tree } \\
\hline $95(<)$ & $\begin{array}{c}< \\
t^{*}=57 \\
57-53 \text { catastrophes, which means } \\
0-4 \text { periods without any catastrophe }\end{array}$ & $<$ \\
\hline $105(>)$ & $>$ & $>$ \\
\hline
\end{tabular}

Signs $>,<,=$ are used to show that the parameter, the optimal time or the value of implementing the policy is higher, lower or equal than in the base case.

an the "worst" cases, i.e. when $\left(t^{*}-x\right)$ previous catastrophes have already occurred (which means $0-x$ periods without any catastrophe).

${ }^{\mathrm{b}}$ Only building dikes means that there is neither emission reduction nor different growth path after implementing the policy. Note that here we conserve the same capital costs as for implementing a policy to reduce $1.1 \%$ of emissions.

Table 3 also shows that, if there are no catastrophes or if the catastrophes are not serially correlated (that is, no WAIS collapse), emission reduction is postponed. That is, the possibility of a WAIS collapse increases optimal emission reduction.

Emission reduction is postponed too, if the policy intervention is adaptation (dike building) rather than mitigation (emission reduction). This is because mitigation 
would reduce the probability of catastrophes as well as non-catastrophic damages, whereas adaptation would reduce the damage due to catastrophes only. For more details about plausible responses (more exactly according to the cost and/or the political feasibility of adaptation as compared to emission reductions) to the threat of rapid sea-level rise, see Lonsdale et al. (2008) for the Thames estuary, Poumadère et al. (2008) for the Rhone delta, and Olsthoorn et al. (2008) for the Rhine delta.

Finally, Table 3 shows that the date of implementation is independent of the intensity of emission reduction. However, social costs decrease with higher emission reduction. The base case policy of Table 2 may be optimal in the timing, but not in the level of emission abatement.

\section{Concluding remarks}

We use a stylized model of the costs and benefits of emission reduction, with large and endogenous uncertainty, with irreversible emission reduction and irreversible climate change impacts, to assess the optimal timing of policy. This was done before. However, we introduce serial correlation into the stochastic process that generates catastrophes, increasing the irreversibility on the climate change impact side. In this manner, we approximate the effects of a possible collapse of the West-Antarctic Ice Sheet.

We confirm the findings of previous studies that catastrophic risks justify greenhouse gas emission reduction. We extend that result to show that catastrophic scenarios (here represented as serially correlated catastrophic risks) justify even greater emission reduction.

The model used is highly stylised. One improvement would be to include technological progress. If endogenous and irreversible-both reasonable assumptionsthe model dynamics would be more complicated still, and the results may differ. Other improvements include a better parameterisation of the model and a more realistic representation of the physical and economic processes. A greater intellectual challenge is to merge our approach, which emphasizes stochasticity, sunk costs and the timing of policy but has a static and discrete representation of emission reduction, with the alternative school of decision making under catastrophic risk (e.g., Keller et al. 2004), which has dynamic and continuous emission reduction but downplays stochasticity, sunk costs and timing.

Acknowledgements We are grateful to Uwe Schneider, Ferenc Toth, Klaus Keller, Steve Schneider and two anonymous referees for helpful comments. CEC DG Research under the Atlantis Project (EVK-CT-2002-000138) and the Michael Otto Foundation for Environmental Protection provided financial support. The opinions and results are the authors' alone.

Open Access This article is distributed under the terms of the Creative Commons Attribution Noncommercial License which permits any noncommercial use, distribution, and reproduction in any medium, provided the original author(s) and source are credited.

\section{References}

Alley RB, Marotzke J, Nordhaus WD, Overpeck JT, Peteet DM, Pielke RA, Pierrehumbert RT, Rhines PB, Stocker TF, Talley LD, Wallace JM (2003) Abrupt climate change. Science 299(5615):2005-2010

Arrow KJ, Fischer AC (1974) Environmental preservation, uncertainty and irreversibility. Q J Econ 88:312-319 
Baranzini A, Chesney M, Morisset J (2003) The impact of possible climate catastrophes on global warming policy. Energy Policy 31:691-701

De Angelis H, Skarca P (2003) Glacier surge after ice shelf collapse. Science 299(5612):1560-1562

Dixit AK, Pindyck RS (1994) Investment under uncertainty. Princeton University Press, Princeton

Fisher AC, Narain U (2003) Global warming, endogenous risk, and irreversibility. Environ Resour Econ 25(7):395-416

Gjerde J, Grepperud S, Kverndokk S (1999) Optimal climate policy under the possibility of a catastrophe. Resour Energy Econ 21:289-317

Harvey D, Huang Z (1995) Evaluation of the potential impact of methane clathrate destabilization on future global warming. J Geophys Res 100:2905-2926

Henry C (1974) Investment decisions under uncertainty: the irreversibility effect. Am Econ Rev 64:1006-1012

IPCC (2001) Climate change 2001: the scientific basis: summary for policy-makers-a report of Working Group 1 on the Intergovernmental Panel on Climate Change

Keller K, Bolker BM, Bradford DF (2004) Uncertain climate thresholds and optimal economic growth. J Environ Econ Manage 48:723-741s

Kolstad CD (1996) Learning and stocks effects in environmental regulation: the case of greenhouse gas emissions. J Environ Econ Manage 31:1-18

Lonsdale KG, Downing TE, Nicholls RJ, Parker D, Vafeidis AT, Dawson R, Hall J (2008) Plausible responses to the threat of rapid sea-level rise for the Thames Estuary. Clim Change. doi:10.1007/s10584-008-9483-0

Nordhaus WD (1994) Managing the global commons: the economics of climate change. MIT, Cambridge, MA

Nordhaus WD, Boyer J (2000) Warming the world: economic models of global warming. MIT, Cambridge, MA

Olsthoorn AA, van der Werff PE, Bouwer LM, Huitema D (2008) Neo-Atlantis: the Netherlands under a five meter sea level rise. Clim Change. doi:10.1007/s10584-008-9423-Z

Oppenheimer M (1998) Global warming and the stability of the West Antarctic ice sheet. Nature 393:322-325

Pindyck RS (2000) Irreversibilities and the timing of environmental policy. Resour Energy Econ 22:233-259

Pindyck RS (2002) Optimal timing problems in environmental economics. J Econ Dyn Control 26:1677-1697

Poumadère M, Mays C, Pfeifle G, Vafeidis AT (2008) Worst case scenario as stakeholder decision support: a 5-6 meter sea level rise in the Rhone delta, France. Clim Change. doi:10.1007/s10584-008-9446-5

Saphores J-D (2004) Environmental uncertainty and the timing of environmental policy. Natural Resource Modeling 17(2):163-190

Schimmelpfennig D (1995) The option value of renewable energy - the case of climate change. Energy Econ 17(7):311-317

Smith JB, Schellnhuber H-J, Mirza MMQ, Fankhauser S, Leemans R, Lin E, Ogallo L, Pittock B, Richels RG, Rosenzweig C, Tol RSJ, Weyant JP, Yohe GW (2001) Vulnerability to climate change and reasons for concern: a synthesis, Chapter 19. In: McCarthy JJ, Canziani OF, Leary NA, Dokken DJ, White KS (eds) Climate change 2001: impacts, adaptation, and vulnerability. Cambridge University Press, Cambridge, pp 913-967

Tol RSJ (2002a) Estimates of the damage costs of climate change. Part I: benchmark estimates. Environ Resour Econ 21:47-73

Tol RSJ (2002b) Estimates of the damage costs of climate change. Part II: dynamic estimates. Environ Resour Econ 21:135-160

Tol RSJ (2008) An emission intensity protocol for climate change: an application of FUND. Climate Policy 4:269-287

Tsur Y, Zemel A (1996) Accounting for global warming risks: resource management under event uncertainty. J Econ Dyn Control 20(6-7):1289-1305

Werey C (2000) Politiques de renouvellement des réseaux d'eau potable. $\mathrm{PhD}$ thesis, Strasbourg University

Wright EL, Erickson JD (2003) Incorporating catastrophes into integrated assessment: science, impacts, and adaptation. Clim Change 57:265-286

Yin R, Newman DH (1996) The effect of catastrophic risk on forest investment decisions. J Environ Econ Manage 31:186-197 